\title{
Determinantes das decisões locacionais da atividade financeira
}

\author{
Michel Alexandre \\ Doutorando em Economia da Università degli Studi di Siena (Itália) \\ Gilberto Tadeu Lima \\ Professor do Departamento de Economia da FEA-USP \\ Otaviano Canuto \\ Diretor-executivo no Banco Mundial \\ e Professor (licenciado) do Departamento de Economia da FEA-USP
}

\section{Palauras-chave \\ instituições financeiras, decisões locacionais, geografia econômica.}

Classificação JEL G20, R10.

\section{Key words}

financial institutions, location decisions, economic geography.

JEL Classification G20, R10.

\section{Resumo}

O presente artigo-resenha versa sobre fatores variados que influenciam as decisões locacionais das instituições financeiras, sendo o foco naqueles que lhes são específicos e não aplicáveis à atividade econômica como um todo.

\section{Abstract}

This review-paper deals with different factors that have an effect on location decisions made by financial institutions. Emphasis is given to those factors that are specific to the financial sector and not applicable to economic activity in general. 


\section{1_Introdução}

Até aproximadamente os anos 80 do século passado, com poucas exceções, ${ }^{1}$ a chamada "geografia do dinheiro" era um tema um tanto quanto negligenciado. Boa parte dessa negligência pode ser explicado pelo fato de, até então, os estudos de economia regional basearem-se fundamentalmente na teoria neoclássica do crescimento. Supondo-se que capital, trabalho e fluxo de informações movem-se livremente e sem custos entre regiões, não há por que se esperar que o dinheiro tenha algum papel relevante no plano regional (Martin, 1999).

A partir de meados dos anos 70, no entanto, a maior parte dos países industrializados começou a passar por importantes reestruturações em seus sistemas financeiros, com significativas alterações de ordem geográfico-espacial. Isso fez crescer o interesse pelos aspectos financeiros da geografia econômica. Assim, principalmente a partir do final da década de 1980, geógrafos e economistas começaram a realizar vários estudos que versavam sobre temas como diferenças regionais nas taxas de juros, fluxos inter-regionais de fundos e disponibilidade regional de crédito. ${ }^{2}$ Atualmente, esse ramo da economia regional já está bem consolidado como subdisciplina.

O traço mais marcante desse processo é a grande onda de fusões e aquisições (F\&A), que reduziu substancialmen- te o número de bancos na Europa e nos Estados Unidos (ECB, 2000). No bojo de tais mudanças, estão avanços tecnológicos em comunicações e tecnologia da informação (TI), que acirraram a competição entre os bancos e os estimularam a entrar em mercados geograficamente distantes de suas sedes, e um afrouxamento da regulamentação financeira, que ampliou o espaço geográfico disponível para a atuação dos bancos e reduziu os custos de transação (Alessandrini et al., 2003).

Essa reconfiguração espacial da atividade financeira não se limitou apenas aos sistemas financeiros nacionais, como também alcançou uma dimensão internacional. A interpenetração geográfica entre os grandes centros financeiros mundiais caiu sensivelmente. Segundo Choi et al. (2002), desde meados dos anos 90 até 2000, o número de bancos estrangeiros nos principais centros financeiros mundiais diminuiu, após 30 anos de crescimento. A recente onda de $\mathrm{F} \& A$ entre grandes bancos contribuiu para esse processo por meio de duas vias:

i. geralmente, as fusões ocorrem entre bancos sediados na mesma cidade, o que lhes permite consolidarem suas atividades naquele centro específico;

ii. às vezes, a aquisição resulta no deslocamento de uma sede bancária de um centro financeiro para uma

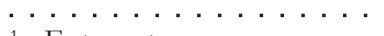
1 Entre estas, merecem destaque as obras de August Losch, The Economics of Location (1939 e 1954), e de Gunnar Myrdal, Economic Theory and Underdeveloped Regions (1957), que ja tratavam de alguns aspectos financeiros da geografia econômica.

2 Para mais detalhes sobre os estudos seminais na área da geografia financeira, ver Martin (1999). 
praça menor, como ocorreu com a aquisição do National Westminster Bank, sediado em Londres, pelo Royal Bank of Scotland, com sede em Edimburgo, em 2000.

A exemplo do sucedido em outros países, o Brasil também passou recentemente por um processo de reestruturação financeira, tendo alguns determinantes peculiares, tais como perda das receitas inflacionárias; abertura financeira ao exterior; programas adotados pelas autoridades de supervisão bancária (PROES e PROER), com a finalidade de sanear o sistema financeiro, e a explosão da dívida pública, permitindo aos bancos altas receitas com títulos públicos. Também houve uma contrapartida geográfica desse processo, marcada por um aumento da concentração do crédito na região Sudeste do País (Vasconcelos et al., 2003).

Além dos elementos de ordem tecnológica e regulatória tratados superficialmente até aqui, esse processo de redistribuição espacial da atividade financeira é explicado pelos movimentos da própria atividade econômica como um todo. $\mathrm{O}$ declínio de Tóquio como praça financeira nos anos 90 explica-se parcialmente pelo enfraquecimento da economia japonesa, o que reduz as perspectivas de ganhos de bancos estrangeiros (Choi et al., 2002). No entanto, os determinantes lo- cacionais específicos da atividade financeira parecem ser mais relevantes, fazendo com que, eventualmente, o movimento financeiro desalinhe-se do movimento da atividade econômica em geral.

Como exemplo, pode ser apresentado o caso brasileiro. A Tabela 1 a seguir expõe alguns dados sobre a evolução da distribuição geográfica do PIB e da atividade bancária no Brasil. Nela, podemos observar alguns fatos que corroboram com a hipótese levantada no parágrafo acima:

_ o Estado de São Paulo teve sua participação no PIB nacional reduzida de 38\% para 34\% no período analisado (1988 a 2000). No entanto, nesse mesmo período, sua participação no crédito bancário aumentou de $30 \%$ para $50 \%$. Note-se também que a concentração do crédito e dos depósitos bancários no Estado é muito superior à concentração do PIB;

- paralelamente, o Estado do Rio de Janeiro, mesmo tendo ampliado ligeiramente sua participação no PIB nacional (de 11\% para 12,5\%), sofreu forte evasão da atividade bancária. A participação do Estado nos depósitos bancários caiu de $11,5 \%$ para $10 \%$, e a queda na participação relativa ao crédito bancário foi ainda mais acentuada: de $25 \%$ para $9 \%$. 
Tabela 1_ Distribuição regional do PIB e da atividade bancária no Brasil: alguns indicadores (em \%)

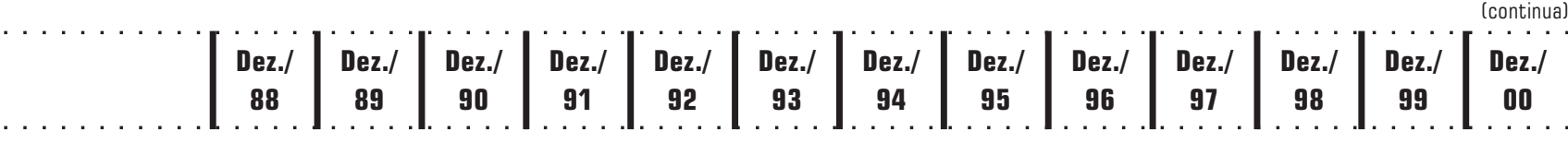

Estado de São Paulo

\begin{tabular}{l|c|c|c|c|c|c|c|c|c|c|c|c|c}
\hline PIB & 38,1 & 37,8 & 37,0 & 35,3 & 35,5 & 34,9 & 34,1 & 35,5 & 34,9 & 35,5 & 35,5 & 34,9 & 33,7 \\
\hline Depósitos & 54,4 & 51,5 & 53,9 & 53,4 & 54,3 & 56,3 & 49,2 & 50,9 & 54,3 & 55,1 & 51,3 & 51,6 & 53,3 \\
\hline $\begin{array}{l}\text { Operações de } \\
\text { Crédito }\end{array}$ & 30,3 & 34,9 & 37,0 & 36,7 & 40,4 & 43,0 & 47,7 & 46,1 & 55,3 & 42,8 & 48,5 & 48,6 & 50,0 \\
\hline Agências & 29,7 & 28,3 & 29,1 & 29,6 & 29,7 & 29,9 & 29,8 & 29,1 & 29,8 & 30,4 & 31,3 & 31,9 & 32,4 \\
\hline
\end{tabular}

Estado do Rio de Janeiro

\begin{tabular}{l|c|c|c|c|c|c|c|c|c|c|c|c|c}
\hline PIB & 11,0 & 10,3 & 10,9 & 12,3 & 12,1 & 11,8 & 11,3 & 11,5 & 11,1 & 11,2 & 11,0 & 11,7 & 12,5 \\
\hline Depósitos & 11,5 & 13,8 & 10,8 & 10,8 & 13,2 & 12,8 & 11,8 & 13,0 & 12,9 & 10,9 & 11,4 & 11,1 & 9,8 \\
\hline $\begin{array}{l}\text { Operações de } \\
\text { Crédito }\end{array}$ & 25,4 & 25,4 & 20,3 & 20,9 & 18,4 & 17,6 & 9,2 & 8,9 & 5,9 & 9,8 & 8,6 & 9,3 \\
\hline Agências & 7,9 & 8,0 & 8,2 & 8,5 & 8,5 & 8,5 & 8,5 & 8,4 & 8,5 & 8,7 & 8,9 & 9,2 & 9,5 \\
\hline
\end{tabular}

Minas Gerais e Espírito Santo

\begin{tabular}{l|r|r|r|r|r|r|r|r|r|r|r|r|r}
\hline PIB & 11,2 & 11,3 & 11,0 & 11,2 & 11,2 & 11,1 & 11,8 & 11,7 & 12,0 & 11,9 & 11,7 & 11,6 & 11,6 \\
\hline Depósitos & 7,5 & 6,1 & 7,7 & 7,6 & 8,7 & 9,3 & 8,6 & 5,3 & 4,8 & 5,3 & 5,8 & 6,7 & 6,2 \\
\hline $\begin{array}{l}\text { Operações de } \\
\text { Crédito }\end{array}$ & 6,7 & 7,0 & 7,0 & 6,1 & 6,2 & 6,3 & 7,2 & 6,2 & 5,1 & 6,9 & 5,9 & 6,2 & 6,3 \\
\hline Agências & 13,1 & 12,8 & 13,4 & 11,6 & 11,5 & 11,5 & 12,3 & 12,7 & 12,9 & 12,9 & 12,9 & 12,7 & 12,6 \\
\hline
\end{tabular}

Região Sul

\begin{tabular}{l|c|c|c|c|c|c|c|c|c|c|c|c|c}
\hline PIB & 17,5 & 18,6 & 18,2 & 17,1 & 18,3 & 18,4 & 18,7 & 17,9 & 18,0 & 17,7 & 17,5 & 17,7 & 17,6 \\
\hline Depósitos & 12,4 & 13,1 & 11,4 & 10,6 & 8,4 & 8,3 & 9,7 & 10,6 & 8,9 & 10,0 & 12,2 & 10,6 & 10,0 \\
\hline $\begin{array}{l}\text { Operações } \\
\text { de Crédito }\end{array}$ & 12,8 & 12,5 & 12,2 & 12,3 & 12,6 & 11,8 & 13,8 & 14,7 & 13,4 & 12,7 & 13,1 & 12,6 & 12,2 \\
\hline Agências & 19,9 & 20,9 & 20,6 & 21,4 & 21,3 & 21,3 & 21,1 & 21,4 & 21,0 & 20,6 & 21,1 & 20,9 & 20,6 \\
\hline
\end{tabular}


Tabela 1_Distribuição regional do PIB e da atividade bancária no Brasil: alguns indicadores (em \%)

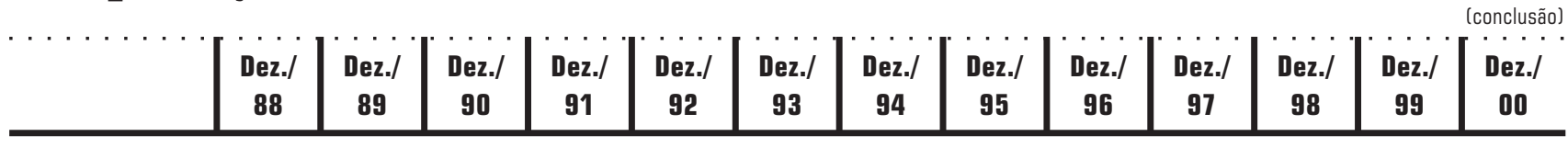

\begin{tabular}{|c|c|c|c|c|c|c|c|c|c|c|c|c|c|}
\hline \multicolumn{14}{|c|}{ Região Nordeste } \\
\hline PIB & 12,8 & 12,3 & 12,9 & 13,4 & 12,9 & 12,8 & 12,9 & 12,8 & 13,2 & 13,1 & 13,1 & 13,1 & 13,1 \\
\hline Depósitos & 5,8 & 5,0 & 7,3 & 7,8 & 7,8 & 6,8 & 6,4 & 5,1 & 10,0 & 7,6 & 7,0 & 7,2 & 7,2 \\
\hline $\begin{array}{l}\text { Operações } \\
\text { de Crédito }\end{array}$ & 8,1 & 7,7 & 10,2 & 9,6 & 9,3 & 8,4 & 9,6 & 10,7 & 8,7 & 13,6 & 9,6 & 9,0 & 8,2 \\
\hline Agências & 17,6 & 17,7 & 16,7 & 16,5 & 16,5 & 16,3 & 16,0 & 16,1 & 15,8 & 15,4 & 14,8 & 14,5 & 14,2 \\
\hline
\end{tabular}

Região Centro-Oeste

\begin{tabular}{l|r|r|r|r|r|r|r|r|r|r|r|r|r}
\hline PIB & 5,0 & 4,8 & 5,2 & 6,1 & 5,7 & 5,8 & 6,1 & 6,0 & 6,1 & 6,2 & 6,8 & 6,4 & 7,0 \\
\hline Depósitos & 7,5 & 10,1 & 7,9 & 8,8 & 6,7 & 5,8 & 13,4 & 14,0 & 8,2 & 9,9 & 11,1 & 11,2 & 12,1 \\
\hline $\begin{array}{l}\text { Operações } \\
\text { de Crédito }\end{array}$ & 15,6 & 11,8 & 12,4 & 12,9 & 11,8 & 11,5 & 11,2 & 12,1 & 8,1 & 12,3 & 12,5 & 12,8 & 12,7 \\
\hline Agências & 7,6 & 8,0 & 7,7 & 8,2 & 8,2 & 8,2 & 8,2 & 8,2 & 8,0 & 8,0 & 7,5 & 7,4 & 7,3 \\
\hline
\end{tabular}

Região Norte

\begin{tabular}{|c|c|c|c|c|c|c|c|c|c|c|c|c|c|}
\hline PIB & 4,4 & 4,9 & 4,9 & 4,7 & 4,3 & 5,2 & 5,1 & 4,6 & 4,6 & 4,4 & 4,5 & 4,4 & 4,6 \\
\hline Depósitos & 0,8 & 0,5 & 1,0 & 1,1 & 0,9 & 0,8 & 0,9 & 1,0 & 1,0 & 1,2 & 1,2 & 1,5 & 1,5 \\
\hline $\begin{array}{l}\text { Operações } \\
\text { de Crédito }\end{array}$ & 1,0 & 0,9 & 1,0 & 1,4 & 1,3 & 1,3 & 1,3 & 1,2 & 3,6 & 1,9 & 1,9 & 1,5 & 1,4 \\
\hline Agências & 4,3 & 4,3 & 4,3 & 4,3 & 4,2 & 4,2 & 4,2 & 4,1 & 4,0 & 3,9 & 3,5 & 3,5 & 3,4 \\
\hline
\end{tabular}

Fonte: Instituto Brasileiro de Geografia e Estatística (IBGE) e Banco Central do Brasil (BACEN). 
Dentro dessa perspectiva, o presente artigo-resenha versa sobre os elementos que influenciam as decisões locacionais das instituições financeiras, com o foco naqueles que lhes sejam específicos e não aplicáveis à atividade econômica como um todo.

A distribuição espacial da atividade financeira dependerá do posicionamento das instituições financeiras diante de duas questões, as quais serão tratadas aqui:

i. quais são os fatores que influenciam a diversificação/concentração geográfica das instituições financeiras;

ii. o que leva uma instituição financeira a se instalar em determinada(s) localidade(s), e não em outra(s).

Há, na literatura econômica, abundantes elementos que permitem responder à primeira questão. Vários fatores são apontados como relevantes na decisão das instituições financeiras entre concentrar ou diversificar suas atividades, os quais serão tratados, a seguir, na seção 2: aspectos regulatórios, sinergias, questões relativas a riscos, trade-off entre "controle" e "custos de agência associados a distância" e progresso tecnológico.

Por outro lado, textos que tratam sobre centros financeiros trazem evidências a respeito das razões pelas quais certas localidades mostram-se bastante atra- tivas às instituições financeiras e acabam por tornarem-se grandes centros financeiros. Em outras palavras, há elementos que explicam por que boa parte das instituições financeiras prefere se estabelecer em Nova York, Londres ou São Paulo, e não em outras praças quaisquer. Tais fatores estariam ligados a desenvolvimento econômico, desregulamentação financeira, economias de aglomeração e externalidades. Esses pontos serão tratados na seção 3. Por fim, considerações finais tomam a última seção.

\section{2_Fatores que influenciam diversificação/concentração da atividade financeira}

\section{1_Aspectos regulatórios}

Questões regulatórias podem influenciar as decisões locacionais das instituições financeiras. Segundo Martin (1999), durante os anos 80 e 90, uma forte onda de desregulamentação (concatenada a um subseqüente processo de re-regulamentação) iniciou-se nos Estados Unidos e na Inglaterra e, logo em seguida, espalhou-se a outros países, tanto desenvolvidos quanto em desenvolvimento. Em linhas gerais, esse processo caracterizouse por abolição ou relaxamento de restri- 
3 Para mais detalhes sobre o caso norte-americano, ver Saunders (2000), capítulo 21.

4 Tais limites, porém, foram sendo gradualmente eliminados. Em 1995, apenas 11 Estados ainda mantinham restrições dessa natureza: Arkansas, Colorado, Geórgia, Iowa, Kentucky, Minnesota, Montana, Nebraska, Dakota do Norte, Oklahoma e Wyoming (Saunders, 2000). ções ao movimento de capitais, desregulamentação do mercado de ações, desmantelamento do mercado financeiro, remoção de controles sobre as operações das instituições financeiras, diminuição da presença do Estado no setor financeiro e acordos internacionais sobre a adequação de capital para instituições financeiras. Como conseqüência, os sistemas financeiros nacionais foram redesenhados espacialmente. De modo geral, eles se tornaram mais geograficamente descentralizados, bancos locais perderam força, aumentou o número de call centres nacionais e de bancos "supra-regionais" através de fusões e aquisições, crises financeiras locais tornaram-se mais freqüentes, surgiram espaços de exclusão financeira e, como resultado, fontes alternativas locais de financiamento, como mercados informais de crédito.

A experiência norte-americana é, talvez, a que melhor permite analisar o impacto de arranjos regulatórios na disposição geográfica da atividade financeira. ${ }^{3} \mathrm{Nas}$ duas primeiras décadas do século XX, melhorias tecnológicas e maior demanda por serviços bancários resultaram num grande crescimento do número de agências bancárias. Essa expansão geográfica dos bancos mostrou-se prejudicial tanto aos bancos pequenos, cujas ati- vidades de varejo eram ameaçadas pelas agências dos bancos maiores, quanto aos grandes bancos dos centros financeiros, que podiam perder espaço em atividades como serviço de compensação de cheques. Em razão de pressões por parte dessas duas categorias, vários Estados norte-americanos implantaram limites à expansão intra-estadual das atividades bancárias. ${ }^{4}$ A expansão geográfica interestadual também foi limitada, com a Lei McFadden de 1927. Muitos bancos procuraram driblar tais restrições através da abertura, em outros Estados, de subsidiárias bancárias e não bancárias, em vez de agências. Desde então, vários fatos de caráter regulatório abrandaram as restrições à expansão geográfica das instituições financeiras nos Estados Unidos, como pactos bancários regionais e nacionais, a aprovação da Lei Garn-St. Germain em 1982 e da Firrea em 1989 (permitiam que bancos adquirissem bancos falidos ou em dificuldades, mesmo que sediados em outros Estados), a aprovação da Lei de Igualdade de Competição Bancária em 1987 (permitia a grandes bancos a aquisição de um banco de serviços integral em outro Estado) e a aprovação da Lei Riegle-Neal em 1994, que permite a bancos norte-americanos e estrangeiros, a partir de $1^{\circ}$ de junho de 1997, abrir agên- 
cias em outros Estados, desde que possam consolidar subsidiárias bancárias em uma rede de agências e/ou adquirir bancos por meio de fusão ou incorporação).

O sistema financeiro da Itália também passou por um importante processo de reconfiguração espacial, no qual aspectos regulatórios tiveram papel fundamental. Segundo Alessandrini e Zazzaro (1999), os bancos italianos, a partir de meados dos anos 80 , foram afetados por mudanças de ordem legal, administrativa e institucional, tais como privatizações, introdução do modelo de "banco universal" e liberalização do mercado de crédito. Isso levou a um aumento da concorrência bancária, abertura de novas agências, fusões e aquisições, take-overs e acordos bancários. Do ponto de vista geográfico, observou-se que:

i. os bancos sediados na região mais rica (o Centro-Norte) tiveram maior penetração nas demais regiões, ao passo que os bancos do Mezzogiorno aumentaram o número de agências apenas em sua própria região, o que evidenciou a fraqueza desses bancos;

ii. os bancos locais, em todas as regiões, perderam parcela de mercado, principalmente nas áreas mais ricas (Lombardia e Lazio) e mais pobres (Mezzogiorno).
No Brasil, há essencialmente dois aspectos regulatórios que procuram influenciar as decisões locacionais das instituições financeiras. Primeiro, a abertura de agências por parte de bancos estrangeiros instalados no País que resulte em um número de agências superior ao de 5/10/1988 fica condicionada à promulgação da lei complementar prevista no artigo 192 da Constituição Federal. ${ }^{5}$ E, em segundo lugar, para instituições financeiras com sede e pelo menos $70 \%$ das dependências fora dos Estados de São Paulo e do Rio de Janeiro, o capital mínimo exigido é $30 \%$ menor. $^{6}$

\section{2_ Sinergias}

A ocorrência de uma fusão pode permitir que as instituições financeiras envolvidas nela usufruam sinergias.

Quando uma F\&A inclui duas (ou mais) instituições que atuam em áreas geográficas distintas, as mudanças administrativas que normalmente se seguem a esse processo geralmente alteram a política de alocação espacial dos recursos da nova instituição, resultando em abertura/fechamento de agências em algumas localidades, redistribuição regional do crédito e de outros produtos financeiros, etc. Segundo Vasconcelos et al. (2003), a forte concentração de crédito bancário no Sudeste brasileiro, ocorrida na última déca- $\cdots \cdots \cdots \cdots$ Regulamento Anexo III, Resolução 2.099 (17/08/94) do Banco Central do Brasil, art. 17.

6 Regulamento Anexo II, Resolução 2.099 (17/08/94) do Banco Central do Brasil, $\int 2^{\circ}$ do art. 1 . 
7 As eficiências do tipo X são "reduções de custo não diretamente atribuíveis a economias de escopo ou economias de escala. Como tal, são geralmente atribuídas a habilidades superiores de gestão e outros fatores gerenciais de difícil mensuração" (Saunders, 2000, p. 467). da, deve-se, em boa parte, à aquisição de bancos com marcada atuação regional por bancos sediados na região. A mudança do controle desses bancos para o Sudeste fez com que as operações de crédito também fossem deslocadas para essa região.

As sinergias podem ser de dois tipos: de custo e de receita. Às sinergias de custo estão relacionadas as economias de escala, de escopo ou fontes de eficiência gerencial (também chamadas de eficiências do tipo X). ${ }^{7}$

Possibilidades de ganhos de escala e de escopo costumam ser grande incentivo a fusões bancárias (Smith e Walter, 1996). Na Europa, a busca por economias de escala ligadas a custos foi a principal motivação para as F\&As que ocorreram intrafronteiras, e a formação de conglomerados internacionais objetivou essencialmente o usufruto de economias de escopo (ECB, 2000). Economias de escala em empréstimos até seriam uma das explicações para a existência de intermediários financeiros (Stanhouse, 1993). A ocorrência de economias de escala e escopo, no entanto, é controversa, principalmente no caso destas últimas.

Vários trabalhos comprovaram empiricamente a existência de economias de escala e, em alguns casos, de escopo. Bos e Kolari (2003) concluíram que potenciais ganhos de eficiência são possíveis via expansão geográfica de grandes bancos europeus e norte-americanos, graças à existência de economias de escala e de escopo. Um estudo de Silva e Neto (2001) constatou existir economias de escala no sistema bancário brasileiro após o Plano Real, independentemente do porte do banco. Moshirian (1999) mostrou como o custo de alguns produtos financeiros pode ser reduzido por economias de escala e de escopo, associadas à competição financeira internacional. Mahajan et al. (1996) constataram que há economias de escala nos bancos multinacionais instalados nos Estados Unidos. Altunbas e Molyneux (1996) encontraram fortes evidências de economias de escala nos sistemas bancários da França, da Alemanha e da Espanha. Lang e Welzel (1996), ao analisarem o sistema bancário alemão, concluíram que há economias de escala em todos os tamanhos de bancos, e economias de escopo nos bancos universais. Delfino (1997) evidenciou a existência de economias de escala no sistema bancário argentino. Karafolas e Mantakas (1996) fizeram a mesma constatação para o caso grego, mas apenas no que se refere a custos operacionais. Economias de escala ligadas a custos operacionais também foram detectadas na Finlândia por Zardkoohi e Kolari (1994). 
Todavia, outros trabalhos (Fields et al. [1993], Berger e Humphrey [1992]) não constataram a ocorrência de ganhos significativos com economias de escala e de escopo. Hanweck e Hogan (1996) não encontraram evidências de economias de escopo na indústria de seguros.

Em boa parte dos estudos empíricos, as economias de escala aparecem associadas a instituições financeiras menores. Trabalhos como os de Durkin e Elliehausen (1998) e Allen e Rai (1996) encontraram evidências de economia de escala apenas em instituições financeiras de pequeno porte. Catlett e Jansen (1996) concluíram que há deseconomias de escala nos bancos do estado norte-americano do Kansas com ativo superior a US\$ 100 milhões. Hanweck e Hogan (1996) detectaram economias de escala em pequenas firmas do mercado de seguros, e deseconomias de escala no caso das grandes.

Intuitivamente, as sinergias de custo são mais pronunciadas quando a fusão ocorre em mercados geográficos próximos ou idênticos, já que o fechamento de agências seria mais intenso, caso os bancos que se fundiram atuassem em áreas sobrepostas. No entanto, um estudo de Berger e Humphrey (1992), ao avaliar 57 megafusões ocorridas entre 1981 e 1989, constatou que as reduções de custos em fusões que envolvem mercados sobrepostos não são maiores que aquelas em fusões que abrangem mercados geograficamente diferentes. Outra conclusão importante foi a de que as reduções de custo estão relacionadas essencialmente a aumentos de eficiência gerencial.

As sinergias de receita estão relacionadas a três fatores:

i. pode haver aumento nas receitas, na hipótese de um banco adquirir outro banco localizado num mercado em crescimento;

ii. o fluxo de receita normalmente torna-se mais estável quando as operações ativas e passivas do banco estão diversificadas geograficamente, já que com isso seu risco diminuirá (a relação entre diversificação geográfica e redução do risco será melhor discutida na seção seguinte);

iii. as receitas podem aumentar, caso o banco se expanda para um mercado com concorrência menos que perfeita.

Um estudo de Reboredo (1997) constatou empiricamente que a expectativa de maiores lucros, ou seja, que sinergias de receita foram relevantes para explicar as ondas de fusões bancárias ocorridas na Espanha durante os anos 1990. 


\section{3_ Questões relativas a riscos}

Há, essencialmente, três tipos de risco que são levados em conta pela instituição financeira: o idiossincrático, o de mercado local e o sistêmico. E os três são influenciados pelo grau de concentração/diversificação geográfica dessa instituição.

O risco idiossincrático, que é aquele inerente à própria instituição, pode ser reduzido por qualquer fusão, independentemente de essa envolver bancos que atuem em mercados sobrepostos ou não. De fato, quanto maior o número de clientes que o banco atende, menor o efeito da quebra de um deles sobre as receitas do banco. Já o risco de mercado local apenas poderá ser reduzido, caso a fusão envolva áreas geográficas distintas. Se dois ou mais bancos que atuem no mesmo mercado realizarem uma fusão, a instituição resultante continuará vulnerável aos riscos típicos daquele mercado. Portanto, enquanto a redução do risco idiossincrático está associada a ganhos de escala, a redução do risco de mercado local requer diversificação geográfica das operações financeiras.

Logo, a diversificação geográfica de suas atividades permite à instituição financeira diluir os riscos associados a mercados locais. Esse benefício pode vir não só do lado das operações ativas, mas também do lado das operações passivas das instituições financeiras. Suponha-se, por exemplo, que depositantes de diferentes localidades apresentem comportamentos distintos, de modo que eles necessitem de dinheiro e façam saques bancários em diferentes épocas. Desse modo, o passivo de um banco cujas operações estivessem diversificadas espacialmente apresentaria menores flutuações ao longo do tempo (Carlson, 2001).

Hipoteticamente, bancos pequenos beneficiam-se mais com ganhos de escala do que os grandes. Estes últimos já operam em grande escala, e o ganho marginal que teriam ao ampliá-la seria pequeno. Dentro dessa lógica, bancos pequenos teriam de se preocupar mais com os ganhos de escala, e os grandes, com a diversificação geográfica. O trabalho de Emmons et al. (2001) corrobora essa idéia. Esse estudo simulou fusões entre pequenos bancos tanto dentro quanto entre mercados locais. Separando os efeitos dos ganhos de escala e da diversificação geográfica sobre a redução do risco, concluiu-se que os primeiros são bem mais significativos que os segundos. O trabalho de Ozkan-Gunay (1998), analisando o sistema bancário turco, também constatou a existência de economias de escala em bancos pequenos e deseconomias de 
escala em médios e grandes bancos. Portanto, a diversificação geográfica traz maiores benefícios marginais para bancos de maior porte.

No entanto, apesar das vantagens da diversificação geográfica apontadas acima, alguns estudos constataram empiricamente que bancos com amplas redes de agências são mais vulneráveis a riscos sistêmicos. Carlson (2001) estudou a falência e a sobrevivência de unit banks e de branch banks norte-americanos durante a Grande Depressão e concluiu que os últimos mostraram maior probabilidade de falência. A razão seria o fato de que os branch banks tendem a manter baixo nível de reservas como proporção dos depósitos. Assim, ainda que em períodos normais os bancos com mais agências sejam mais seguros, em épocas de choques sistêmicos como a Grande Depressão eles tornam-se mais suscetíveis a quebrar.

O trabalho de Hughes et al. (1996) coloca que o efeito da expansão geográfica sobre a vulnerabilidade do banco a choques sistêmicos dependerá essencialmente de sua eficiência. O risco de quebra seria, portanto, preponderantemente endógeno. Trabalhando com bancos norte-americanos, o estudo conclui que o simples aumento do número de agências, não necessariamente acompanhado de expansão geográfica, eleva o risco de insolvência em bancos eficientes. $\mathrm{O}$ aumento do número de Estados nos quais o banco atua tem efeito insignificante sobre o risco de insolvência. Já para bancos ineficientes, o aumento no número de agências diminui o risco de insolvência e aumenta a eficiência, ao passo que o aumento no número de Estados nos quais o banco atua aumenta o risco de insolvência e tem efeito insignificante sobre a eficiência.

Portanto, a mera expansão do número de agências contribui para a redução do risco idiossincrático do banco. Para que haja redução do risco de mercado local, no entanto, essa expansão deve ser acompanhada de diversificação geográfica. Apesar dessas vantagens, bancos com maiores redes de agência podem, dentro de certas circunstâncias, ser mais vulneráveis ao risco sistêmico.

\section{4_ "Trade-off" entre "controle" e "custos de agência associados a distância"}

Berger e DeYoung (2001) avaliam os efeitos da expansão geográfica sobre a eficiência dos bancos. Nesse trabalho, os autores fazem duas definições:

i. controle: é a capacidade dos administradores seniores da instituição em repassar suas habilidades administrativas, políticas e procedimentos às agências; 
$\ldots$ administrativa utilizado aqui corresponde às chamadas eficiências de tipo X, já tratadas anteriormente.

9 Os Estados Unidos são um excelente laboratório para se avaliar os efeitos da expansão geográfica bancária, já que se trata de um país extenso com uma grande distância entre os bancos da mesma bolding companie. ii. custos de agência associados a distância: são os custos adicionais ou as receitas perdidas que surgem quando os administradores seniores têm maior dificuldade em monitorar ou controlar administradores locais de uma grande distância.

Hipoteticamente, uma instituição financeira com alto controle e dotada de administradores eficientes poderia obter ganhos significativos com a expansão geográfica de três maneiras:

i. seus administradores estariam aplicando suas práticas eficientes ${ }^{8}$ sobre uma maior massa de recursos;

ii. a firma aproveitaria economias de rede, através da interligação entre agências, automated teller machines (ATMs) e escritórios;

iii. diversificaria seu risco (questão já tratada anteriormente).

Por outro lado, a expansão geográfica estaria ampliando os custos de agência associados a distância. Esse problema pode aparecer por várias razões: os administradores podem atuar em mercados nos quais eles possuem menor competência; deseconomias organizacionais podem surgir (por exemplo, custos em se monitorar administradores iniciantes em agências distantes); ou a distância pode dificultar o provimento de serviços relati- onship-based a clientes locais. Desse modo, a expansão geográfica seria benéfica ao banco, caso as vantagens trazidas pelo controle e pela eficiência superassem os custos de agência associados a distância.

A conclusão do estudo, que avaliou mais de sete mil bancos norte-americanos entre 1993 e $1998,{ }^{9}$ é a de que o controle tende a se dissipar com a maior distância da agência. No entanto, os efeitos dos custos de agência sobre a eficiência são pequenos, sugerindo que bancos eficientes conseguem suprimir malefícios advindos de maior distância. Isso implica que não há um escopo geográfico ótimo para bancos, podendo esses operar eficientemente em áreas geográficas amplas ou mais restritas.

\section{5_Progresso tecnológico}

O aprimoramento da tecnologia utilizada pela instituição financeira permite um controle mais eficiente sobre agências localizadas em pontos distantes da matriz e, portanto, costuma estar positivamente associado à diversificação geográfica financeira.

Um estudo dos mesmos autores citados acima (Berger e DeYoung, 2002) avaliou os efeitos do progresso tecnológico sobre a expansão geográfica dos bancos norte-americanos entre 1985 e 1998. Eles utilizam os conceitos de "controle" e de "custos de agência associados a distância", já definidos anteriormente. O es- 
tudo conclui que o progresso tecnológico não só amplia o controle dos administradores seniores sobre suas filiadas, como também reduz os custos de agência associados a distância, facilitando, portanto, a expansão geográfica.

\section{3_Formação, manutenção e expansão de centros financeiros}

\subsection{Desenvolvimento econômico}

O desenvolvimento econômico é um fator intimamente ligado ao florescimento da atividade financeira. Conforme atesta Porteous (1999), historicamente, centros financeiros se desenvolveram para suprir as necessidades de serviços financeiros da economia real - agricultura, indústria e mineração. No entanto, a pujança da atividade econômica é um importante suporte não só para o nascimento, mas também para o posterior desenvolvimento da atividade financeira.

Uma explicação para esse fato é de cunho keynesiano e está apresentada em dois trabalhos de Amado (1998 e 1999). Em áreas de menor dinamismo econômico, há maior preferência pela liquidez, dada a maior incerteza e os arranjos institucionais menos desenvolvidos. Por outro lado, essas áreas tendem a perder liquidez para as áreas mais dinâmicas, seja por motivos reais (balança comercial), seja por motivos financeiros (conta de capitais). Desse modo, bancos localizados em áreas de baixo dinamismo enfrentam dois problemas:

i. perdem mais reservas para o público do que os bancos localizados nas áreas dinâmicas, em razão da preferência pela liquidez nas áreas menos dinâmicas;

ii. perdem reservas para as áreas dinâmicas.

Transpondo esse modelo para um espaço regional, conclui-se que as atividades bancárias (e financeiras, de modo geral) tenderão a se concentrar nas localidades mais dinâmicas economicamente.

Tais apontamentos foram constatados empiricamente para o caso brasileiro. Sicsú e Crocco (2003) concluíram, mediante estudo empírico, que o volume de renda monetária, assim como sua distribuição espacial e pessoal, explica em boa medida a distribuição das agências bancárias no Brasil. Castro (2002), estudando cinco regiões metropolitanas brasileiras (São Paulo, Rio de Janeiro, Belo Horizonte, Salvador e Curitiba) durante o período 1988/2000, concluiu que, quanto maior o dinamismo econômico da região e sua produtividade média do trabalho, maior sua capacidade em reter depósitos e menor sua preferência pela liquidez. Assim, tais regiões concentram 
boa parte da atividade financeira. São Paulo foi apontada como a mais central e dinâmica, com a maior capacidade de retenção de depósitos e menor preferência pela liquidez. Isso, em parte, explicaria o fato de a região concentrar $72 \%$ dos head-offices dos bancos do País. Em épocas de menor incerteza macroeconômica e maior crescimento do País, as áreas mais dinâmicas tendem a ampliar, ou ao menos manter, suas vantagens com relação às demais áreas no que diz respeito à concentração da atividade financeira.

É provável que esses elementos se alimentem mutuamente, ou seja, que o desenvolvimento financeiro resulte em maior crescimento econômico. Analisando os determinantes das taxas de crescimento dos municípios brasileiros durante 1980-1991, o trabalho de Toneto Jr. e Chagas (2002) concluiu que municípios com maior taxa de especialização econômica apresentaram taxas de crescimento econômico superiores. Pode-se inferir de tal resultado que áreas especializadas em atividades financeiras apresentariam um crescimento econômico mais robusto. No entanto, as evidências empíricas de tal hipótese são controversas.

Alguns estudos, como o de Shan et al. (2001), consideram que não é possível fazer uma conclusão geral sobre a relação finanças - crescimento. Analisando a recente reestruturação bancária ocor- rida na Itália, que resultou, entre outras coisas, em maior penetração de grandes bancos em regiões periféricas do país, Alessandrini et al. (2003) chegaram a um apontamento semelhante. Segundo os autores, não é possível abraçar ou excluir nem a abordagem "otimista", pela qual a maior competição seleciona os bancos mais eficientes, nem a teoria "pessimista", que sustenta que os grandes bancos são incapazes de se adaptar às necessidades específicas das áreas periféricas.

No entanto, o trabalho de Guiso et al. (2002) testou especificamente se um alto grau de especialização financeira gera crescimento econômico. A conclusão foi a de que o desenvolvimento financeiro aumenta a probabilidade de um indivíduo começar seu próprio negócio, favorece a entrada, faz crescer a competição e, por todas essas razões, promove o crescimento econômico. Constatou-se também que esse efeito é mais relevante no caso de pequenas firmas, já que grandes empresas podem adquirir financiamento em outras praças.

Resultados semelhantes foram obtidos para o caso brasileiro pelo estudo de Matos (2002). Trabalhando com dados relativos ao período $1947 / 2000$, o autor concluiu que, em geral, há uma relação causal positiva, unidirecional e significativa entre desenvolvimento financeiro e crescimento econômico. Os resultados 
mais relevantes foram obtidos quando as medidas de desenvolvimento financeiro utilizadas foram crédito bancário ao setor privado/PIB e ativos do público confiados ao sistema financeiro/M2. Isso destaca a importância do sistema financeiro como intermediador de recursos e da confiança do público nas instituições financeiras. Em trabalho mais recente (Matos, 2003), lidando com dados trimestrais de 1980-2002, o autor confirmou tais apontamentos, encontrando efeitos bidirecionais significativos entre desenvolvimento financeiro e crescimento econômico, no caso brasileiro.

\section{2_Desregulamentação financeira}

A desregulamentação dos mercados financeiros traz efeitos benéficos para o florescimento e a expansão das praças financeiras.

Warf (2000) trata do exemplo da cidade de Nova York. Segundo o autor, a base financeira da região fortaleceu-se a partir dos anos 70 com a desregulamentação das finanças. Tal desregulamentação incluiu os Securities Acts Amendments de 1975, a Depository Institutions Deregulation e o Monetary Control Act em 1980 e o Garn-St. German Act em 1982. O relaxamento das restrições às atividades bancárias interestaduais favoreceu Nova York, cujos bancos puderam penetrar em mercados locais dos Estados Unidos. Outras mudanças foram: remoção das restrições aos portfólios de fundos de pensão e fundos mútuos, abolição das comissões fixas nas transações das Bolsas de Valores, aprovação da presença de capital estrangeiro nessas bolsas e o debate sobre a eliminação da Lei Glass-Steagall, que separou bancos comerciais de bancos de investimento desde 1933.

Outro caso que pode ser citado é o dos principais centros financeiros europeus: Londres, Frankfurt e Paris. Em outubro de 1986, ocorreu o chamado "Big Bang", nome dado à grande desregulamentação das atividades financeiras em Londres. Uma de suas principais mudanças foi a introdução do Stock Exchange Automated Quotation (SEAQ), um sistema informatizado para o comércio de títulos britânicos. Após o "Big Bang", ocorreu uma grande corrida dos bancos para a compra de firmas corretoras.

À época, era clara a vantagem de Londres sobre seus rivais continentais. No entanto, Paris e Frankfurt começaram a eliminar várias restrições à realização de atividades financeiras, como requerimentos de reserva mínima para contratos de recompra, que tornava algumas transações de renda fixa muito caras, a proibição do comércio de derivativos e, no caso alemão, a fragmentação do mercado de ações (as Bolsas de Frankfurt e 
Dusseldorf negociavam volumes similares). A Alemanha introduziu uma série de leis para promover os mercados financeiros. A França, por sua vez, batalhou para que o título de dívida pública francês fosse o benchmark europeu. Todas essas mudanças diminuíram as diferenças entre os centros financeiros de Paris e Frankfurt com relação a Londres.

No entanto, Londres ainda se beneficia com as restrições mais amenas à atividade econômica vigentes na Inglaterra. França e Alemanha apresentam restrições significativas no que diz respeito a impostos (altas taxas de imposto de renda), bancos (forte presença do Estado no sistema bancário) e (no caso da França) fluxos de capital. Na Inglaterra, por sua vez, as restrições são menos severas. Isso favorece Londres como praça financeira, em detrimento de seus concorrentes.

\section{3_Economias de aglomeração e externalidades}

As instituições financeiras tendem a se localizar em praças onde já exista elevada concentração financeira para usufruir economias de aglomeração. Fattouh (2001) chegou a essa conclusão, ao estudar os determinantes da localização de bancos nos principais centros financeiros do mundo. A proximidade física e a interação mais direta com seus concorrentes permitiriam ao banco desfrutar do spillover informacional e das externalidades geradas por essa maior concentração financeira. Além disso, a concentração geográfica de bancos geralmente leva a mercados interbancários mais líquidos e eficientes. Choi et al. (2002) corroboram essa hipótese, ao constatar que o número de bancos em um centro permanece como um grande fator de atratividade para outros bancos.

Tabela 2_Liberdade das condições econômicas: fluxo de capitais, impostos e bancos

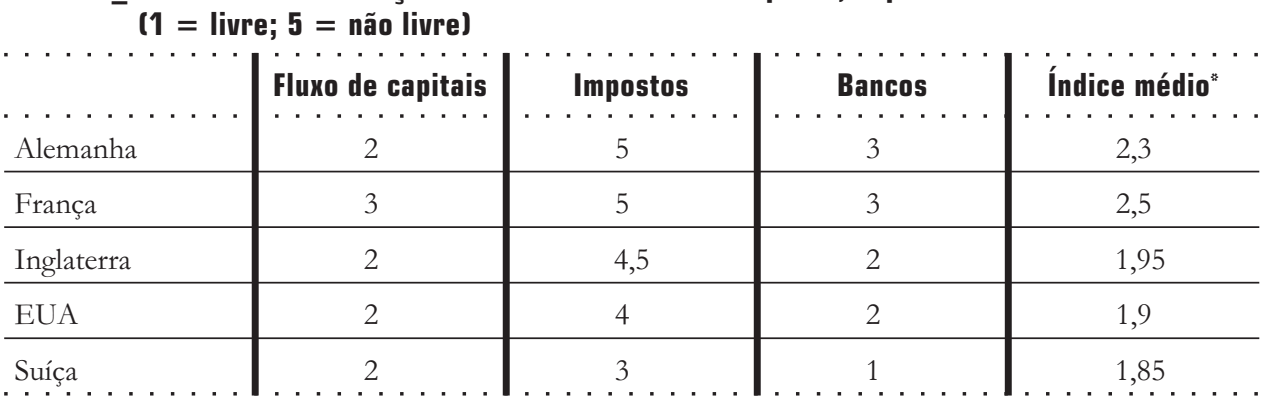

(*) Total de oito fatores incluídos.

Fonte: 1999 Index of Economic Freedom. 
Entre as externalidades que atraem bancos a uma determinada praça, destaca-se a infra-estrutura que dá suporte às operações financeiras. Warf (2000) coloca que Nova York conta com infra-estrutura tecnológica avançada, que permite às instituições financeiras nela instaladas realizar grandes operações financeiras num curto espaço de tempo. As firmas financeiras contam com telecomunicações para realizar suas operações via redes internacionais. Elas se valem de redes eletrônicas de transferência de fundos para movimentar capitais instantaneamente, arbitrar entre diferentes taxas de juros e tirar vantagens de taxas de câmbio favoráveis. Uma rede global de linhas de fibra ótica liga Nova York a outros centros financeiros importantes, como Londres. Todo esse aparato permite a movimentação de uma grande soma de recursos (estimado em US\$ 3 trilhões diários) por todo o globo rapidamente.

Londres conta com uma importante Bolsa de Futuros e Opções, a London International Financial Futures and Options Exchange (LIFFE) desde o início dos anos 80. Seu sistema SEAQ, já mencionado, movimenta parcela cada vez maior dos títulos europeus. Para não ficar atrás de Londres, Paris e Frankfurt implantaram recentemente sistemas eletrônicos de comércio de títulos. Atualmente, a in- fra-estrutura de mercado dos centros financeiros continentais da Europa é tão boa quanto a de Londres, e, em alguns aspectos, até melhor.

Outra importante externalidade que beneficia as instituições financeiras de determinada praça é o capital humano. Gehrig (1998) trata da importância da presença de profissionais qualificados em centros financeiros para a sobrevivência desses. Com os avanços tecnológicos, os custos de transação caem, e a expansão geográfica das atividades financeiras é, portanto, facilitada. De acordo com essa lógica, as operações financeiras não precisariam mais se concentrar em determinados espaços físicos, e os centros financeiros tenderiam a minguar.

No entanto, o autor faz uma distinção entre "informação simples padronizada" (ISP) e "informação complexa sofisticada" (ICS). Enquanto a primeira é facilmente compreendida e pode ser facilmente disseminada eletronicamente, a segunda é mais difícil de transmitir e requer a proximidade física entre a pessoa que a transmite e a que a recebe. Assim, atividades que dependem de ISP tendem a se dissipar geograficamente à medida que a tecnologia avança. Contudo, as atividades relacionadas aos chamados títulos "informacionalmente sensitivos", tais como ações e derivativos, cuja correta ava- 
liação depende de ICS, tendem a se concentrar localmente junto a especialistas e experts capazes de analisar devidamente os retornos futuros esperados desses títulos.

Portanto, os centros financeiros, segundo Gehrig (1998), concentrarão essencialmente as atividades relacionadas a títulos "informacionalmente sensitivos". $\mathrm{E}$ a capacidade desses centros em atrair tais atividades dependerá principalmente de sua disponibilidade de especialistas aptos a gerar e a transmitir ICS.

Em consonância com esse ponto de vista, Tschoegl (2000) aponta que o desenvolvimento de novas tecnologias alterou a distribuição espacial das atividades financeiras de acordo com a natureza dessas atividades. Enquanto atividades que envolvem processos rotinizados, transações em pequena escala e padronização dispersaram-se dos grandes centros financeiros, outras que envolvem processos inovadores, transações em larga escala e customização continuam a ser desenvolvidas em importantes centros financeiros, em razão da presença de externalidades importantes a essas atividades nesses centros.

\section{4_Considerações finais}

Este estudo procurou identificar, dentro da literatura existente, os determinantes locacionais da atividade financeira, abor- dando seu duplo aspecto: elementos que influenciam a concentração/dispersão espacial da atividade financeira e fatores de atratividade local à atividade financeira. O grau de dispersão espacial das instituições financeiras resulta da ponderação entre as vantagens (sinergias, diversificação de riscos, economias de rede, etc.) e as desvantagens (maior exposição ao risco sistêmico, atuação em mercados geográficos desconhecidos, etc.) da diversificação geográfica. Quanto às localidades que concentram a atividade financeira, essas em geral estão em regiões de alto grau de desenvolvimento econômico e possuem ambiente regulatório propício à atividade financeira. No entanto, enquanto atividades financeiras intensivas em tecnologia se concentram principalmente em grandes centros, onde usufruem externalidades essenciais ao seu desenvolvimento, tais como mão-de-obra qualificada e infra-estrutura tecnológica, o mesmo não ocorre necessariamente com atividades mais simples e padronizadas. 


\section{Referências bibliográficas}

ALESSANDRINI, P.; PAPI, L.; ZAZZARO, A. Banks, regions and development. Banca Narionale del Lavoro Quarterly Review, n. 224, Mar. 2003.

ALESSANDRINI, P. ZAZZARO, A. A "possibilist" approach to local financial systems and regional development: the Italian experience. In: MARTIN, R. (Org.). Money and the space economy. Wiley. West Sussex, 1999.

ALLEN, L.; RAI, A. Operational efficiency in banking: An international comparison. Journal of Banking \& Finance, v. 20, n. 4 , p. 655-672, May 1996

ALTUNBAS, Y.; MOLYNEUX, P. Cost economies in EU Banking Systems. Journal of Economics \& Business, v. 48, n. 3, p. 217-230, Aug. 1996.

AMADO, A. M. Impactos regionais do recente processo de concentração bancária no Brasil. In: ENEP, 3., 1998, Niterói. Anais... Niterói, 1998.

AMADO, A. M. Moeda, sistema financeiro e trajetórias de desenvolvimento regional desigual. In: LIMA, G. T.; SICSÚ, J.; PAULA, L. F. (Orgs.).

Macroeconomia moderna: Keynes e a economia contemporânea. Rio de Janeiro: Campus, 1999.
BERGER, A.; DEYOUNG, R. The effects of geographic expansion on bank efficiency. The Federal Reserve Board. Finance and Economics Discussion Series 2001-3. 2001.

BERGER, A.; DeYOUNG, R. Technological progress and the geographic expansion in the banking industry. The Federal Reserve of Chicago. Working Paper Series. WP-02-07. June 2002.

BERGER, A.; HUMPHREY, D. B. Megamergers in banking and the use of cost efficiency as an antitrust defense. The Anti Trust Bulletin, n. 37, p. 541-600, 1992.

BOS, J. W. B.; KOLARI, J. Large bank efficiency in Europe and the United States: Are there economic motivations for geographic expansion in financial services? De Nederlandsche Bank, Research Series Supervision, n:. 61, July 2003.

CARLSON, M. Are branch banks better survivors? Evidence from the Depression Era. The Federal Reserve Board. Finance and Economics Discussion Series 2001-51. Nov. 2001.
CASTRO, C. B. Moeda e espaco: os casos das áreas metropolitanas de São Paulo, Rio de Janeiro, Belo Horizonte, Curitiba, Salvador e suas áreas de polarização. 2002. Dissertação (Mestrado) - CEDEPLAR, Universidade Federal de Minas Gerais, Belo Horizonte, 2002.

CATLETT, R. B.; JANSSEN, A $\mathrm{J}$. Economies of scale and scope in Kansas Banking. Journal of Economics, v. 22, n. 1, p. 31-35, 1996

CHOI, S. R.; PARK, D.; TSCHOEGL, A. E. Banks and the world's major banking centers, 2000. The Wharton Financial Institutions Center, Working Paper Series. July 2002.

DELFINO, J. A. Economia de escala y de producción conjunta en las entidades financieras. Un análisis empírico del sistema bancario. Cuadernos de Economía, v. 34, n.101, p. 87-100, Apr. 1997.

DURKIN, T. A.

ELIIEHAUSEN, G. E.

The cost structure of the consumer finance Industry. Journal of Financial Services Research, v. 13 , n. 1 , p. $71-86$, Feb. 1998
EMMONS, W. R.; GILBERT, R. A.; YEAGER, T. J. The importance of scale economies and geographic diversification in community bank mergers. The Federal Reserve Bank of St. Louis. Working Paper 2001-024A. Nov. 2001.

EUROPEAN CENTRAL BANK (ECB). Mergers and acquisitions involving the EU banking industry - facts and implications. Dec. 2000.

FATTOUH, B. Determinants of banks' location in the world's major financial centres. University of London, Centre for Financial and Management Studies. Discussion Paper 09, SOAS, 2001

FIELDS, J. A.; MURPHY, N. B. TIRTIROGLU, D. An

international comparison of scale economies in banking: Evidence from Turkey. Journal of Financial Services Research, v. 7, n. 2 , p. 111-125, June 1993.

GEHRIG, T. Cities and the geography of financial centers. CEPR Discussion Paper, n. 1894 June 1998.

GUISO, L.; SAPIENZA, P.; ZINGALES, L. Does local financial development matter? NBER Working Paper 8923 , May 2002. 
HANWECK, G. A.; HOGAN, A. $\mathrm{M} B$. The structure of the property/casualty insurance industry. Journal of Economics \& Business, v. 48, n. 2, p. 141-155, May 1996

HUGHES, J. P.; LANG, W.; MESTER, L.; MOON, C. Safety in numbers? Geographic diversification and bank insolvency risk. Federal Reserve Bank of Philadelphia, Working Paper 1996-14. May 1996.

KARAFOLAS, S.; MANTAKAS, G. A note on cost structure and economies of scale in Greek banking. Journal of Banking \& Finance, v. 20, n. 2, p. 377-387, Mar. 1996

LANG, G.; WELZEL, P. Efficiency and technical progress in banking: Empirical results for a panel of German Cooperative Banks. Journal of Banking \& Finance, v. 20, n. 6, p. 1003-1023, July 1996.

LOSCH, August. The Economics of Location. New Haven: Yale U. P. 1954.

MAHAJAN, Arvind; RANGAN, Nanda; ZARDKOOHI, Asghar. Cost structures in multinational and domestic banking. Journal of Banking \& Finance, v. 20, n. 2, p. 283-306, Mar. 1996

MARTIN, R. Introduction. In: MARTIN, R. (Org.). Money and the space economy. Wiley: West Sussex, 1999.
MATOS, O. C. Desenvolvimento do sistema financeiro e crescimento econômico no Brasil: evidências de causalidade. Banco Central do Brasil, Trabalho $\mathrm{p} /$ discussão $n^{\circ} 49$, set. 2002.

MATOS, O. C. Inter-relações entre desenvolvimento financeiro, exportações e crescimento econômico: análise da experiência brasileira. Notas Técnicas do Banco Central do Brasil, n. 40, out. 2003.

MYRDAL, Gunnar. Economic Theory and Under-Developed Regions. London: Duckworth, 1957.

MOSHIRIAN, F. International financial services. Journal of International Financial Markets, Institutions \& Money, v. 9, n. 3, p. 217-221, Aug. 1999.

\section{OZKAN-GUNAY, E N.}

Economies of scale and scope in the Turkish Banking Industry: The effect of the financial liberalization program. Journal of Economics, v. 24, n. 1, p. 67-84, 1998.

\section{PORTEOUS, D. The} development of financial centres: Location, information externalities and path dependence. In: MARTIN, R. (Org.).

Money and the space economy. Wiley: West Sussex, 1999.

\section{REBOREDO, J. C. Incentives to} merge and Bank Soundness. The case of the Spanish savings banks. Universitat Autónoma de Barcelona, DEHA/IAE.

Discussion Paper: 371/97. Apr. 1997.
SAUNDERS, A. Administracão de instituições financeiras. 1. ed. São Paulo: Atlas, 2000.

SHAN, J. Z.; MORRIS, A. G.; SUN, F. Financial development and economic growth: An egg-and-chicken problem? Review of International Economics, v. 9, n. 3, p. 443-454, 2001

SICSÚ, J.; CROCCO, M. Em busca de uma teoria da localização das agências bancárias: algumas evidências do caso brasileiro. Economia, v. 4, n.1, jan./jun. 2003.

SILVA, T. L.; NETO, P. M. J.

Economia de escala nos bancos brasileiros após o Plano Real. Texto para Discussão 227. CAEN UFC. Fortaleza, jul. 2001.

SMITH, R. C.; WALTER, I. Global patterns of mergers and acquisition activity in the financial services industry. New York

University, Salomon Center Working Papers: S/96/48, 1996.

STANHOUSE, B. E. Credit evaluation, information production, and financial intermediation. Journal of Financial Services Research, v. 7, n. 3, p. 217-233, Sept. 1993.

TONETO JR., R.; CHAGAS, A. L. S. Crescimento local e especialização da atividade econômica - evidências a partir de dados dos municípios brasileiros no período 1980 a 1991. In: ENEP, 7., 2002, Curitiba. Anais... Curitiba, 2002.
TSCHOEGL, A. International banking centers. Geography, and foreign banks. Financial Markets, Institutions \& Instruments, v. 9, Issue 1, Feb. 2000.

VASCONCELOS, M.; FUCIDJI, J. R.; SCORZAFAVE, L. G.; ASSIS, D. L. O todo e as partes: distribuição regional e determinantes do crédito bancário brasileiro: uma análise com dados em painel. In: ENCONTRO REGIONAL DE ECONOMIA DA REGIÃO SUL, 6., 2003, Curitiba. Anais... Curitiba, set. 2003.

WARF, B. New York: the Big Apple in the 1990s. Geoforum 31, p. 487-499, 2000.

\section{ZARDKOOHI, Asghar;} KOLARI, James. Branch office economies of scale and scope: Evidence from savings banks in Finland. Journal of Banking \& Finance, v. 18, n. 3, p. 421-432, May 1994. 